\title{
Testing powers of engagement
}

\section{Green living experiments, the ontological turn and the undoability of involvement}

Noortje Marres, Goldsmiths, University of London

This article was published in L. Adkins and C. Lury (Eds.) (2009) Special issue on 'What is the empirical? European Journal of Social Theory 12 (1): 117-133.

\begin{abstract}
This paper explores the role of sustainable living experiments as devices of public engagement. It engages with object-centred perspectives in the sociology of science and technology, which have characterized public experiments as sites for the domestication of technology, and as effective instruments of public involvement, because, in part, of the seductive force of their use of empirical forms of display. Green living experiments, which are conducted in the intimate setting of the home and reported on blogs, complicate this understanding, insofar as they seek to format socio-material practices as sites of involvement. This has implications for how we conceive of the relations between these two phenomena. While socio-material practices are often located outside the public sphere, green living experiments extend the publicity genre of "being intimate in public" to things. It also follows that green living experiments do not so much solve but rather articulate problems of public involvement.
\end{abstract}

Key words: sustainable living; object-centred sociology; technologies of public engagement; ontological politics; new media

\section{Introduction}

Why would anyone let a smart electricity meter into their home? In recent years, a host of freelance writers, environmentalists and technology enthusiasts have taken it upon themselves to provide extensive answers to this question, on the 
Web and in other publicity media. Most of them are careful to consider both the pro's and con's of this household addition, noting, among other disadvantages, the disquiet caused by a sizable display in the living room that provides constant updates of money spent and $\mathrm{CO} 2$ emitted as a consequence of routine domestic activities, like boiling the kettle. However, on the whole these publicists tend to praise smart meters, mainly for providing a feasible way for people to get involved with environmental issues, and with the societal projects currently undertaken in their name: the green revolution, the transition to a sustainable society, the making of the low-carbon economy, and so on. In this respect, I want to suggest here, publicity surrounding smart meters, and green living more generally, presents an interesting case for the sociology of science and technology. In recent years, a lot has been written in this field about the capacities of science and technology to engage publics (Irwin and Michael, 2003; Leach et al., 2005). Some of this research focuses on public experiments, as they are performed in museums, political assemblies and construction sites, suggesting that this particular form of publicity is today widely deployed as a device of engagement. Experiments, this work proposes, are currently valued as a way of making public engagement more 'doable.' As material set-ups, they appeal to people's senses and allow for playfulness, and as such effectively address the challenge of how to draw in easily distracted audiences. That is to say, these studies suggest that it is partly the deployment of empirical forms of display that today serves as a solution to the problem of how to engage publics. 
Many of the themes flagged in social studies of public experiments can be recognized in publicity surrounding sustainable practices in the home, which indeed often takes the form of an experiment. Thus, in recent years, so called 'green living experiments,' in which people set themselves the task of making environmental changes in their lives for a set period of time, have been widely featured in popular media and on the Internet. In this paper, I want to consider these experiments and their deployment as an engagement device, as they raise a number of questions about this special affordance of the public experiment. The fact that in this case public experiments are conducted in the intimate setting of the home, and not in a public place like the museum, can be taken as an invitation to explore these affordances anew. One of the things that is remarkable about green living experiment is that they do not only use material settings for purposes of involvement, they also involve attempts to transform everyday material practices into practices of public involvement. As such, these experiments open up again some questions of the sociology of public experiments, questions about how we should understand the relation between socio-material practices and public involvement, about the significance of empirical forms of display in structuring this relation, as well as about the distinctive competences of sociologists to account for the relations between humans and things. And, in this way, these experiments can also be seen to open up the idea that experiments make public involvement more doable. 


\section{Public experiments as devices of engagement}

In the sociology of science and technology, public experiments have long been recognized as events in which the role of techno-science in society and public life becomes clear (Latour, 1988; Collins, 1988; Barry, 2001). Work in this field has approached public experiments from several different perspectives, with some authors adopting an epistemic viewpoint. Thus, in a well-known study of a public experiment in which a train was deliberately crashed to demonstrate the safety of the transport of nuclear materials by rail, Harry Collins focused on the question of whether this mediatized experiment lived up to norms of scientific knowledge production. It didn't. Others, however, have approached public experiments from what can be called an 'ontological' or 'object-centred' perspective, viewing them as events in which not only new knowledge, but also new entities are introduced to society.

Actor-network theorists like Bruno Latour have argued that public experiments should be understood as ceremonial events, a kind of initiation ritual that structures the process of the domestication of techno-scientific entities in society (Latour, 1988). What is crucial, from this perspective, is that the introduction of new techno-scientific objects to society involves much more than the addition of new knowledge and things to social life. It requires the reconfiguration of the wider social-material relations among which the new object is to be accommodated. This point has consequences both for how we conceive of the experiment as well as of the role of the public in relation to it. Regarding the former, an object-centred understanding of public experiments can 
be taken to imply an approximation of the categories of the empirical and the ontological in such experiments. This is because, if the public experiment is seen as a ritualistic moment in a process of the reconfiguration of social ontologies, this form of knowledge production can no longer be understood in a positivistic spirit, as the other of metaphysics. Instead, the empirical mode of presentation that is characteristic of experiments - involving measurement, recording, visualisation, and detailed reporting - is here seen to enable the performance of a particular form of metaphysics in its own right, one that is characteristic of technological societies. It's an experimental form of metaphysics, one that is done rather than proclaimed, and which involves the tentative shifting of the entities and relations that form the background of social life (Mol, 1999). Such a perspective on experiments also has consequences for how we view the role of the public in relation to it.

A socio-ontological approach to public experiments involves a particular understanding of the relations between the experiment and its public. From this perspective, this relation cannot be viewed as an external one, in the sense that neither the experiment nor the public would be able take or leave the other and remain unaffected. It proposes instead that there exists a relation of dependency between the objects of public experiments and their publics. This is so because, as the domestication of techno-scientific entities in society involves the reordering of socio-material relations, so the process of accommodation requires the active collaboration of social actors. The public experiment must then be seen as an attempt to secure the active involvement of social actors in the process of 
the domestication of science and technology. Moreover, from such a perspective, the relation of publicity between the genre of the experiment and the public domain should also not be viewed as an external one. This is because the phenomenon of the public experiment now cannot be accounted for in terms of the mere transposition into public space of scientific formats for the production and communication of knowledge, if, indeed, this was ever the case. Thus, as Shapin and Schaffer (1989) have shown in their socio-historical analysis of Robert Boyle's demonstration of the air pump, the public experiment has been developed as a genre of publicity from the historical beginnings of modern experimental science onwards. In their account, the invention of the experimental mode of knowledge production already involved the invention of the empirical as a form of publicity - one that revolves around the careful recording of measurements and the reliable description of sensory observation, so as to enable 'virtual witnessing' by wider audiences.

This understanding of the experiment as a distinct public form has been further elaborated in recent studies of public demonstrations (Latour, 2005; Macdonald, 1998; Girard et al, 2007). This work focuses on demonstrations of science and technology in public places, like museums and political assemblies, and proposes that the publicity format of the experiment is today widely appreciated for its capacities to engage audiences. That is, these studies argue that the public experiment should not only be seen as instrument for the socialization of science and technology. Rather, this formula has special affordances as an instrument of public involvement its own right. The 
experiment, then, has exceptional capacities in terms of getting and keeping audiences involved, as compared to other forms of public involvement. And authors like Andrew Barry (1998) have singled out the empirical mode of presentation as especially relevant in this respect.

The public experiment, Barry proposes, engages because it appeals to people's senses, and because, as a material set-up, it addresses audiences as embodied actors, and allows for playful forms of interaction. And it is because the experiment is able to seduce in this way, that it helps to make involvement doable - both for those intent on engaging audiences and the actors who are to be engaged. This is increasingly important, Barry argues, in a time when public institutions must prove their validity by demonstrating that they are able to draw in crowds, and audiences can decide to stay away. Experiments, then, are effective instruments of publicity in a context in which science and technology must seduce audiences if they are to find a place in the world.

Now, in some respects, contemporary green living experiments seem to be perfect instantiations of these claims of the sociology of science and technology. To the extent that green living experiments showcase new domestic technologies like eco-kettles and smart electricity meters, they appear to be an only too literal instance of the attempt to 'domesticate' new technologies in society. And it seems clear that the genre of the experiment is deliberately deployed as a device of public involvement in this case: as I will discuss below, reports of green living experiments routinely celebrate their ability to engage the senses, address people as embodied actors, and induce playfulness. At the same time, however, the ways 
in which these experiments make use of the intimate setting of the home and the popular medium of the blog opens up again the question of how we should conceive of affordances of public experiments for engagement, as well as for the domestication of technology.

\section{Green living and the 'intimization' of public experiments}

The formula of the green living experiment, in which individuals report on their household's attempts to adopt a less environmentally damaging lifestyle, emerged in recent years on so-called 'carbon blogs. ${ }^{, 1}$ Since then, it has been adopted by mainstream media; in the English language media space, the Web's 'No Impact Man,' has been joined by the Guardian's 'Green Guy,' and the BBC's 'Ethical Man.' These publicity projects can be contextualized in a number of different ways. They can be seen in the light of a broader shift in discourses on environment and society, where everyday life is today widely recognized as the proper site for engaging people in green issues (MacNaghten, 2003). But the formula can also be traced back to the literary tradition of ecology writing, in which people keep diary records of the day-to-day progress made in reconnecting with nature (Bowerbank, 1999). When seen in the context of contemporary media, green living experiments may also appear as a progressive version of recent adaptations of domestic social experiments as a popular media format.

Such experiments find their premise in an experimental protocol, as in the case of the blog 'Green As A Thistle', on which the Canadian journalist Vanessa Farquharson reports on her project to 'spend each day, for an entire calendar 
year, doing one thing that betters the environment'. ${ }^{2}$ Many green bloggers subject themselves and their close ones to scripted, out-of-the-ordinary interventions, such as the removal of certain objects from their habitat, like their fridge, paper towels, car or microwave. ${ }^{3}$ And, in the case of green living experiments too, the actions and responses of subjects tend to be extensively recorded and reported by way of photos, videos, writing, lists, and various ways of adding up numbers, on the Web, and in other publicity media. Thus, some green blogs provide detailed graphic representations of people's 'carbon diets,' visualising the amount of energy they consume daily, measured in tonnes of carbon emitted. ${ }^{4}$ In adopting these formulas and representational figures, green living blogs can also be seen to enact a particular form of publicity that sociologists have recognized in reality television, that of 'mediated intimacy' (Wood et al, in press). In the domestic experiments of reality television, intimacy has been said to make possible an ethical discourse of 'self-improvement.' This too might apply to green living experiments, to the extent that they foreground the intimacy of our lives with material objects, from toasters to showerheads. The demonstration of our personal dependency on these things, and thus of certain hidden background conditions of everyday life, here too tends to be framed as an occasion to learn and change one's individual ways. Accordingly, green living experiments are probably best seen as a mixture of different experimental genres and forms, containing elements of technical demonstrations, nature writing, and the social experiments of reality television. 
However, insofar as green living experiments can be viewed as a kind of intimate or 'intimized' version of the public experiment, the question is raised whether this has implications for how we understand its role as a device of public involvement. ${ }^{5}$ Does the circumstance that public experiments are here conducted in the mundane and familiar setting of the home, and reported in the home-grown medium of blogs, make a difference in this regard? More specifically, as these experiments have as their subject matter people's everyday habits and their intimate domestic settings, does this have consequences for the kind of work 'the empirical' is doing here as a genre of publicity?

What seems significant here is that green living experiments tend to enlist domestic environments and objects in the project of engaging actors. Thus, green living blogs continuously stress how engaging domestic things and settings can be, providing endless numbers of pictures and anecdotal accounts of objects exhibiting powers of engagement, from the fridge which only once it is switched off tells of our reliance on it, to a tomato plant on a balcony that adds a homegrown flavour to meals, cardboard boxes which can be turned into children's costumes in a few minutes, and biodegradable cat litter which is hard to get used to because of its smell. ${ }^{6}$ Indeed, in some respects it seems no exaggeration to say that Web accounts of green living experiments provide multiple public demonstrations of the powers of engagement that household objects and devices are capable of exerting on us. This becomes especially clear in accounts of living with smart electricity meters. Thus, several green blogs report on the experience of introducing smart electricity meters intotheir homes, and virtually all of them 
emphasise the special ability of these devices to engage people. Thus, the Green Guy, who lived with three different smart meters for a week, refers to the remark by Dale Vince, the founder of the renewable energy company Ecotricity, who described his experience of bringing a smart meter home, and 'how his wife and two children went round the house switching off lights one by one, watching the watts go down.' And 'how surprised he was by the degree to which it engaged them all. ${ }^{7}$

It is not difficult to recognize in an account like this ideas from the sociology of demonstrations about the efficacy of public experiments as instruments of involvement. Such an account seems to fit well with Andrew Barry's proposal to understand the experiment as an interactive technology that is capable of seducing actors. ${ }^{8}$ But, what is striking about these accounts of life with smart meters is that some of them extend the script of the experimental encounter beyond the dyadic interaction between the experimental device and its subjects. They equally ascribe powers of engagement to domestic settings, and indeed to domestic energy. Thus, smart meters are said to make it possible to enjoy the flow of energy: 'my son in Germany says that one of his greatest pleasures is to see the electricity meter turning backwards as Dachs feeds into the grid. ${ }^{9}$ In another case, the meter is ascribed the ability to bring to life domestic settings, and thereby questions of energy use. Thus, smart meters are said to 'drive home the realisation that devices that heat things, like kettles and toasters, really do lap up the volts, and our homes are full of nasty little things that use electricity without telling us. ${ }^{10}$ Accordingly, experiments in living with smart 
meters can be said to enact public involvement insofar as they confer the capacity to engage not only onto experimental technologies, like the smart meter, but also onto domestic settings, and domestic energy flows. That is, green living experiments can be seen to turn familiar surroundings into an engaging environment, so that the socio-material arrangements of the home can do the work of engaging people.

Now, in some cases, this conferral of the ability to engage is couched in a familiar empirical language, one that draws on the classic trope that 'seeing is believing,' in order to make the point that 'seeing is engaging.' Thus, Peter Armstrong's account of using smart meters at home highlights the way meters make domestic energy use visible in a lively way: 'The display will show $\mathrm{kW}$ being used, cost or the amount of carbon being produced. It provides a really vivid way of seeing the effect of turning on an extra electric fire or leaving too many lights on. ${ }^{11}$ However, the accounts of life with smart meters introduced above seem to deviate from this latter one, to the extent that they do not so much foreground the ability of smart meters to visualize and inform, but rather, their ability to transform the material setting of the home into an engaging place. In this respect, these accounts can be seen to fuse, or perhaps indeed confuse, different modes of being involved: engagement of the senses, by seeing or reading energy consumption measurements; engagement of the body, in the sense of being absorbed in play; and involvement socio-materially speaking, in the sense of being implicated by means of familiar things in the home in energy flows, and the wider issues that it opens up. ${ }^{12}$ Because green living experiments 
produce this particular confusion, they raise questions about the relations between the performance of public involvement, on the one hand, and sociomaterial practices, on the other.

\section{Material practice as a form of public involvement}

The deployment of domestic settings and things in publicity surrounding green living not only raises questions about the role of the experiment as a means of engagement. It also speaks to wider interests in the social sciences in the role of objects as mediators of social, political and moral relations. In recent years, sociologists, anthropologists and philosophers have directed attention to the affordances of technological and scientific objects to enable involvement, both in the sense of human sociability (Knorr Cetina, 1997; Lash and Lury, 2007), and in the moral or political sense of engagement with matters of collective concern (Bennett, 2005; Latour, 2005; Marres, 2007). It is perhaps no coincidence that the latter perspectives have been elaborated in relation to the environment in particular. Thus, social researchers and theorists have written extensively on the merits of things like stoves, strawberry fields, and rubbish bins to enable different modes of relating to, and enacting, issues of sustainability (Verbeek, 2005; Hawkins, 2006). This line of work tends to involve a particular normative commitment, in that it tends to be affirmative of the role of objects as means of involvement. That is to say, this work on objects can be seen as part of a much wider project in social, cultural and political studies, namely the project to establish embodied practices as alternative sites of engagement, and thus to move 
beyond the narrow preoccupation with linguistic interaction that has long marked the social sciences (Thrift, 2008). ${ }^{13}$ Thus, work on objects has much in common with work on space, the body and affect, which questions the preoccupation of a classical kind of critical social science with upholding standards of rational argumentation and the ideal of conscious intent, and seeks to rearticulate questions of involvement as pertaining to embodied actors who are variously situated in socio-technico-materially configured spaces. All these different types of social study, then, are committed to resituating engaged and to-be-engaged subjects in a socially, materially, technically, emotionally, aesthetically 'thicker' world.

But, the notion that socio-material modes of involvement hold out a normative promise over against predominant, deliberative framings of interaction in the public sphere also has a special place in the sociology of science and technology. Thus, Michel Callon and Vololona Rabeharisoa (2004) have opposed the detached modes of engagement characteristic of public debate, to the much more open-ended relations of 'entanglement' that arise between science, technology, bodies and all sorts of other things in social life. Perhaps most crucially, Callon and Rabeharisoa (2004) value socio-material practices for doing without the demand of 'disentanglement' from everyday life, which predominant forms of public participation tend to place on social actors: the requirement that they must extricate themselves from their on-going social lives if they are to participate in a public. In making this point, the authors establish a rather strict analytical distance between public involvement, on the one hand, and socio- 
material entanglement, on the other, and this distance also informs their normative appreciation of entanglement as an alternative form of involvement. Thus, Callon and Rabeharisoa value entanglement precisely to the extent that it is situated 'somewhere else,' and operates on a different level that that of predominant public discourses. They characterize socio-material entanglements as proliferating outside the limelight, subterraneously as it were, in the vaguely defined elsewheres of a social life outside the public sphere. Like other proponents of actor-network theory, then, they view entanglement as an underarticulated phenomenon that is unlikely to ever be recognized as a viable form of involvement in official, public discourses (Law and Mol, 2008). ${ }^{14}$

Now some sociologists have emphasised the cross-overs that may occur between projects of public engagement and practices of socio-material entanglement. Thus, Thrift (2008) and Lash and Lury (2007) have proposed that certain object-centred forms for engaging publics, such as the distribution of freebies and platforms for user-involvement in product design, precisely disrupt the distinction between being implicated and being involved, between being caught up in something socio-materially speaking and being engaged in it as a social or political actor. However, these accounts equally seem to maintain an analytic distance between socio-material entanglement and public involvement, insofar as they too present the former as an aspect of public involvement that remains under-acknowledged in dominant framings of it.

It is precisely this opposition between practices of entanglement and forms of public involvement that green living experiments complicate. They challenge 
the notion that socio-material entanglement largely plays itself out outside the limelight, insofar as they turn 'socio-material entanglement' into an object of public performance. Indeed, the publicity format of the green home experiment seems explicitly designed to articulate relations of dependence between people and things in their habitat and the wider environment, and to present them as a plane on which involvement can take place. In this regard, they arguably involve attempts to reformat public involvement as an enactment of socio-material entanglement. These experiments disrupt the assumption that 'material entanglement' happens at a different level to that at which the frames and procedures of public participation come into play. And in doing so, they complicate the suggestion that socio-material entanglements require sociological description because they are so opaque.

Certainly, green living experiments cannot be said to perform the same tasks as object-centred sociologists, that of describing socio-material relations. They tend to articulate a very particular set of entanglements and not others, as in the case of accounts of smart meters, which tend to focus on 'unnecessary' power consumption and changeable domestic routines. These accounts have little to say about rather more 'constraining' or inescapable entanglements, such as for instance, energy infrastructures and landlords, or the regulatory arrangements of measurement and monitoring that smart meters may or may not enable in the future. They tend to highlight socio-material relations that can be reconfigured through individual intervention, by switching appliances off or installing saving devices, and as such, they may indeed have to be interpreted as dramatizations of 
'self-improvement,' similar to other mediatized home experiments. But, as green living experiments present socio-material practices in the home as sites of public involvement, they raise further questions about the sociological valuation of public experiments as sites of ontological intervention.

\section{The shifting registers of ontology}

This analysis of green living experiments, as involving attempts to turn material practices in the home into sites of public involvement, raises the question of the wider social and political effects of this framing of public engagement. Some authors have answered this question by pointing to the 'effect' of the 'privatization' of citizenship, as it here becomes a matter of domestic consumption. Others have countered that domestic action enables a materialist form of engagement with the environment, which addresses the causes of environmental damage done elsewhere on the planet (Dobson, 2003). However, in approaching green living as a public experiment, we do not have to choose between understanding it as either a 'merely' private practice or as addressing public problems. From this perspective, what seems especially important are the affordances of green living as sites of 'socio-ontological' intervention. As I suggested above, green living experiments can be said to include among their scripted effects the transformation of socio-material relations in the home, and perhaps indeed beyond. Thus, documenting the effects of removing her fridge, Vanessa Farquharson reports on a range of changes of habit and insight, such as her discovery that vegetables hold up surprisingly well when stored in dark places, and that she more or less stopped eating yoghurt. Would it be an 
exaggeration to infer that green living experiments perform the work of reconfiguring socio-ontological relations in public? If not, this re-opens the question of what this type of project entails, insofar as the sociology of science and technology has mostly conceptualized the shifting of ontologies, too, as something that happens outside the limelight, subterraneously.

To discuss this further, it may help to be more precise about some of the different uses of the term 'ontology' in accounts of the relations between science, technology and society. One way of doing this is to distinguish between different levels on which ontology can be situated. To begin with, there is the conceptual level, which is where social theory classically locates it. Ontology then refers to the basic assumptions of social theory regarding the entities and relations that constitute social reality. However, what can equally be located at the conceptual level is the turn to ontology in social theory. Ontology is then about the commitment to take non-human entities seriously as constitutive components of social, epistemic and other phenomena (Schatzki et al., 2001). Importantly, from this perspective, the classic understanding of ontology as a kind of grammar of social reality reveals an 'epistemic' approach to ontology. The latter assumes that the discourse of social theory is the most relevant plane at which the existence of entities is posited. In order to highlight that not just sociological discourses, but also practices and events, provide occasions for the articulation of social entities, a radicalization of the notion of ontology is then necessary (Fraser, 2008). This brings us to a second level on which ontology can be situated, namely the empirical. Here it comes to refer to historical changes in the entities and relations 
that make up social reality, which are then understood to vary over time (and sometimes, space (Mol, 2002)). An 'ontological' perspective on social reality in this case also involves a particular empirical claim, namely that the sociomaterial composition of societies must be understood as dynamic for historical reasons -- not in the least because the development of science and technology over the past centuries has resulted in the proliferation of new entities across societies (Brown, 2003; Latour, 1994).

Thirdly and lastly, some social theorists have talked about ontology in terms of what could be called a 'techno-normative project.' This register of ontology is quite close to the previous one, in that it too directs attention to the changing socio-historical roles of objects in social, moral and political life. However, those who foreground this dimension of ontology are not only concerned with socio-historical changes in the kinds of entities that populate societies. They highlight a particular $20^{\text {th }}$-century development, namely the rise of design regimes under which objects are to be deliberately equipped with moral and political capacities, such as 'the capacity to engage.' Thus, Thrift (2008) and Lury and Lash (2007) have directed attention to contemporary settings where product design meets marketing and publicity campaigning, arguing that objects today are increasingly designed to function as devices of enrolment, as 'thingmedia' that are capable of involving/entangling users with a service, brand, product, political party, leader, and so on. Green living experiments also direct attention to this third register of ontology, insofar as the socio-technical 
assemblage including the home, domestic objects, devices like smart meters, and blogs, here seems to be quite purposefully deployed to enact involvement.

However, green living experiments also invite us to add a further constructive point to accounts of public experiments as sites of socio-ontological intervention. One of the main effects of these accounts in the sociology of science and technology, one could say, was to 'empiricize' ontology, by portraying public experiments as sites where the question of which entities compose the world is given an experimental, historically variable answer. (This is also to say, in providing such accounts, sociologists of science and technology enacted a turn to ontology in multiple registers. These accounts, after all, involve both an empirico-historico claim - about the reconfiguration of worlds as a consequence of the introduction of new techno-scientific objects - and a conceptual shift of perspective - namely the commitment to recognize nonhumans as constituent components of social practices, and to conceive of configurations of humans and non-humans as dynamic 'all the way down. ${ }^{15}$ ) However, in this particular version of what could be called 'empirical ontology,' in a variation on the notion of experimental metaphysics, the role of the public experiment, as a genre of publicity, can appear to be rather limited. Thus, actornetwork theorists like Latour, Mol and Law have tended to characterize, not just material entanglements, but the wider process of socio-ontological change as an inadvertent process, which plays itself out beyond the scope of publicity media. However, in contrast to this, green living experiments can be seen to publicize the process of the reconfiguring relations. One could say that socio-ontological 
change here can be seen to involve constructive labour of its own. That is, the articulation of socio-material relations here relies on a particular socio-technical assemblage of publicity, involving devices like smart meters, a format like the blog, and the place of the home. ${ }^{16}$ Rather than material entanglements proliferating beyond social and public forms, they here figure as an object of dramatization in public. In this respect, these experiments could be taken to remind us that if we are serious about 'empiricizing' ontology, a move in the opposite direction is required as well, that of 'ontologizing' the empirical. Social studies of public demonstrations can be understood as undertaking this second movement. At the very least, they can be said to 'materialize' the empirical, as they direct attention to the affordances of experimental set-ups to facilitate situated, embodied, object-centred practices of public engagement. These studies, then, explore the affordances of this public genre for engaging actors and articulating objects in a material register. Now green living experiments can be taken as an invitation to broaden this exploration, as they raise the question of how empirical forms of publicity are deployed to format everyday material practices as enactments of public involvement. The question, then, is whether and how public forms like measurement, the experimental report, and so on, enable social actors to do ontological work, that is, to articulate and shift socio-material entities and relations. While I am not able to say anything conclusive about this here, it is important to keep in mind, that this kind of project is likely to involve changes in the publicity format of the experiment itself. In this regard, publicity surrounding green living might be seen 
to experiment with the genre of the experiment itself. Thus, green experiments seem to combine the genre of the technical demonstration with the modern literary form of 'public intimacy,' which is characteristic of public letters and diaries. In this respect, they can be said to extend to things the modern publicity format of 'being intimate in public' (Berlant, 1997), enacting intimacy with familiar objects and thereby pulling us in. However, in exploring this form of involvement, green living experiments certainly cannot be taken simply to propose a new solution to the challenge of how to get and keep publics involved, in the form of 'the intimate materiality' of the home. This is because green living blogs, in presenting material practices in the home as sites of public involvement, can also be seen to turn involvement into a problem.As I mentioned, green living has been criticized, both in popular media and academic discourses, for promoting a limited understanding of civic involvement, one centring on individual acts of consumption. However, green living blogs themselves also articulate a number of problems that the attempt to 'do' engagement with the home brings with it. Many emphasise the difficulties and practical limits encountered in performing involvement by physical and material means, and some green blogs present material practices of involvement as intrinsically problematic. Thus, some blogs provide lists of the endless number of things that make domestic subjects complicit in environmentally damaging wastefulness, often without them knowing it, and sometimes, without them being able to do anything about it, such as 'our crap tea-making skills [that] are emitting a lot of pointless carbon. ${ }^{, 17}$; things like aluminium wrappings that push 
up the carbon footprint of chocolate Easter eggs ${ }^{18}$; a water tank that continues to heat water even when you only take cold showers. ${ }^{19}$ The list of environmentally dubious practices and routines can seem practically endless, pointing at a problem of 'uncontainability.' But these blogs also highlight the costs involved in engaging with environmental issues by domestic means. Thus, some bloggers enumerate the pathologies they started suffering from after embarking on green living exercises, from social deviance ('your house smells of vinegar ${ }^{20}$ ), to fixation problems ('I know there is anecdotal evidence across the web that people who have meters installed [..] becom[e] obsessive about it ${ }^{21}$ ), and the problem of getting lost in triviality ('there have been plenty of silly little changes this month — like altering the margins on my Word documents, eating ice cream in a cone rather than a cup and shaving in the sink. ${ }^{22}$ ) Possibly, these lists can be interpreted as an indication that green living exercises destabilize social frames, or relatedly, that they rob people of their sense of proportion, unable to differentiate between the big and the small, the more and the less important (Strathern, 2004 (1994)). More generally speaking, as green blogs document the trivialities, deviance and deceptions involved in practical attempts to engage with the environment, they make it seem practically undoable to perform involvement by material means.

ConclusionGreen living experiments, then, invite us to reconsider the assumption that material forms of involvement are particularly effective ones. 
That is also to say, these experiments can be seen to produce yet another complication for the sociology of science and technology. Green living experiments do not only problematize the normative promises associated with socio-material forms of engagement, because of the ways in which dissolve the distance between material practices and publicity. Equally important, in the context of this paper, is that these experiments themselves assist in the articulation of material entanglement as a problematic mode of involvement. In doing so, they remind us that questions about the 'doability' - the term is Joan Fuijmara's (1987) - of involvement remain very much on the table, when public involvement takes the form of socio-material practice. Material practices bring with them costs and risks of engagement of their own: the risk of futility, obsessiveness, and so on. Enactments of issue involvement by socio-material means, as in green living experiments, may then have to be approached, not as ways of resolving problems of public involvement, but rather as articulations of such problems in practice. This does not exactly simplify matters, as it strengthens rather than helps to resolve a sense of ambivalence in relation to material practices of public involvement. However, at least it does address, to make one last generalization, a broad tendency in the sociology of science and technology: the tendency to dissolve problems of social and political theory rather than re-articulate them. That is, for all their commitment to empirical practices, these perspectives can seem too committed to providing theoretical solutions for practical problems, rather than to describing how these problems are articulated in practice. In this sense, the questions asked in this paper are also 
questions about how 'empirical' the sociology of science and technology itself should be. One way in which it could become more so, would be to take more seriously the fact that sociological problems, such as public involvement, are not only to be solved in theory, but also articulated in practice. From this vantage point, part of the significance of a publicity genre like the green living experiment is that it helps to articulate material forms of involvement as not quite doable but therefore no less worth trying. 


\section{References}

Barry, Andrew (2001) Political Machines. London: Athlone Press.

Barry, Andrew (1998) 'On Interactivity: consumers, citizens and culture', in Sharon Macdonald (ed) The Politics of Display: Museums, Science, Culture. London and New York: Routledge.

Bennett, Jane (2005) 'In Parliament with Things', in Lars Tonder and Lasse Thomassen (eds) Radical Democracy: Politics Between Abundance and Lack. Manchester: Manchester University Press.

Berlant, Lauren (1997) The Queen of America Goes to Washington City: Essays on Sex and Citizenship. Durham: Duke University Press.

Bowerbank, Sylvia (1999) 'Nature Writing as Self-Technology,' in Eric Darier (ed) Discourses of the Environment. Malden: Blackwell Publishers.

Brown, Bill (2003) A Sense of Things: The Object Matter of American Litterature. Chicago: Chicago University Press.

Collins, Harry, (1988) 'Public Experiments and Displays of Virtuosity: The

Core-Set Revisited', Social Studies of Science 18(4): 725-748. 
Callon, Michel and Vololona Rabeharisoa (2004) 'Gino's lesson on humanity: genetics, mutual entanglements and the sociologist's role,' Economy and Society 33(1): 1-27.

Dobson, Andrew (2003) Citizenship and the Environment. Oxford: Oxford University Press.

Girard, Monique and David Stark (2007) 'Socio-technologies of Assembly: Sense-making and Demonstration in Rebuilding Lower Manhattan.' In David Lazer and Viktor Mayer-Schoenberger (eds) Governance and Information: The Rewiring of Governing and Deliberation in the 21st Century. New York and Oxford: Oxford University Press.

Fraser, Mariam (2008) 'Facts, Ethics and Event', in C. Bruun Jensen and K. Rödje (eds) Deleuzian Intersections in Science, Technology and Anthropology. New York and Oxford: Berghahn Books.

Fujimura, Joan H. (1987) 'Constructing `Do-able' Problems in Cancer Research: Articulating Alignment', Social Studies of Science 17(2): 257-293.

Hawkins, Gay (2006) The Ethics of Waste: How We Relate to Rubbish. Lanham: Rowman \& Littlefield Publishers. 
Irwin, Alan and Mike Michael (2003) Science, Social Theory and Public

Knowledge. Milton Keynes: Open University Press.

Knorr Cetina, Karin (1997) 'Sociality with objects: social relations in postsocial knowledge societies', Theory, Culture \& Society 14(4): 1-30.

Latour, Bruno (2005) 'From Realpolitik to Dingpolitik or How to Make Things Public', In Bruno Latour and Peter Weibel (eds) Making Things Public. Cambridge: MIT Press.

Latour, Bruno (1994) We've Never Been Modern. Translated by Chatherine Porter. Cambridge: Harvard University Press.

Latour, Bruno (1988) The Pasteurization of France. Translated by Alan Sheridan and John Law. Cambridge: Harvard University Press.

Lash, Scott and Celia Lury (2007) Global Culture Industry: The Mediation of Things. Cambridge: Polity Press.

Law, John and Annemarie Mol (2008) 'Globalisation in Practice: On the Politics of Boiling Pigswill', Geoforum 1 (39): 133-143. 
Law, John (2004) After Method: Mess in Social Science Research. London and New York: Routledge.

Leach, Melissa, Ian Scoones and Brian Wynne (eds) (2005) Science and Citizens: Globalization and the Challenge of Engagement. London: Zed Books.

Macdonald, Sharon (ed) (1998) The Politics of Display: Museums, Science, Culture. London and New York: Routledge.

Macnaghten, Phil (2003) 'Embodying the environment in everyday life practices', Sociological Review 51 (1): 62-84.

Marres, Noortje (2008) 'Front-staging non-humans: The politics of "green" things and the constraint of publicity', in Bruce Braun and Sarah Whatmore (eds) The Stuff of Politics. Minneapolis: University of Minnesota Press.

Marres, Noortje (2007) 'The Issues Deserve More Credit: Pragmatist Contributions to the Study of Public Involvement', Social Studies of Science 5 (37): 759-780.

Mol, Annemarie (1999) 'Ontological Politics. A word and some questions', in John Law and John Hassard (ed) Actor-network Theory and After. London: Blackwell. 
Mol, Annemarie (2002) The Body Multiple: Ontology In Medical Practice.

Durham: Duke University Press.

Schatzki, Theodore, Karin Knorr Cetina and Eike von Savigny (eds) (2001) The Practice Turn in Contemporary Theory. London and New York: Routledge.

Shapin, Steven and Simon Schaffer (1989) Leviathan and the Air-Pump:

Hobbes, Boyle, and the Experimental Life. Princeton: Princeton University Press.

Shove, Elizabeth (2007) 'Caution: Transitions ahead: politics, practice and sustainable transition management', Environment and Planning A (39): 763-770.

Strathern, Marilyn (2004 (1991)) Partial Connections. Oxford: Rowan \& Littlefield.

Thrift, Nigel (2008) Non-representational Theory: Space, Politics, Affect. New York and London: Routledge.

Verbeek, Peter-Paul (2005) 'Artifacts and Attachment: A Post-Script Philosophy of Mediation', in: Hans Harbers (ed) Inside the Politics of Technology. Amsterdam: University of Amsterdam Press. 
Wood, Helen, Beverley Skeggs and Nancy Thumim, 'It's just sad': Affect, Judgement and Emotional Labour in 'Reality' Television Viewing', in J. Hollows (ed) Homefires: Domesticity, Feminism and Popular Culture. London and New York: Routledge. In press.

\section{Bio}

Noortje Marres is a Marie Curie Research Fellow in Sociology at Goldsmiths, University of London. Her current research is concerned with object-centred forms of publicity and citizenship emerging in relation to climate change. She received her $\mathrm{PhD}$ from the Philosophy Department of the University of Amsterdam, for a thesis about (neo-)pragmatist theories of democracy in a technological society.

Dr Noortje Marres

Centre for the Study of Invention and Social Process

Department of Sociology

Goldsmiths

University of London

New Cross

London SE14 6NW

Contact: n.marres@gold.ac.uk 
${ }^{1}$ There are a number of portals for carbon and green living blogs on the Web:

http://uk.oneworld.net/section/blogs/carbon; http://www.bestgreenblogs.com; http://greenblog.ir/en/

The number of blank green blogs on the Web may be taken as an indication that it is on its way to become a media format.

${ }^{2} \mathrm{http}: / /$ greenasathistle.com/

3 Green living experiments can seem like controlled versions of an effect much discussed in the philosophy and sociology of technology, that of un-blackboxing, the transformation of an intermediary into a mediator. However, in green living experiments the effect plays itself out in a particular way, as it here is used to make the everyday seem interesting. For more about public media as staging political effects that have been described in the sociology of technology, see Marres, 2008

$4 \mathrm{http}: / / \mathrm{www}$. carbondiet.org/tour

5 The notion of the 'intimization' of public experiments resonates with recent debates in sociology and political theory about the implications of the privileging of the home as a site of environmental engagement (Dobson, 2004; Shove, 2007). In this regard, green living blogs may be seen as indications of a wider trend, that of the relocation of environmental citizenship to the 'privatized', and arguably, consumption-oriented setting of the household. However, in this paper I would like to emphasise that green living blogs themselves articulate some of the promises and challenges involved in privileging the home as a site of public involvement. More generally speaking, critiques of green living as a 'merely private' practice are easy to find, in news and online media, and I would say that they are an intrinsic part of the phenomenon. Indeed, my interpretation of green living blogs as public experiments is partly meant to shift the debate on green living beyond a strict opposition between 'private' and public forms of engagement (see also Marres, 2008).

${ }^{6}$ Green as a Thistle, 'The Final Post', February 29, 2008, http://greenasathistle.com/2008/02/29/thefinal-post/

7 Vaughan, Adam, 'Smart meters turn up the heat on those with money to burn', June 14, 2007, http://www.guardian.co.uk/environment/2007/jun/14/energy.utilities

Many reports on life with smart meters have a strong gender bias. In at least three cases, male bloggers brought in their girlfriends to demonstrate that these eco-gadgets are 'really captivating'. In each case, the girl friends were presented as reliable witnesses because they had no interest in technical matters. ${ }^{8}$ The idea that experiments are engaging because they are fun also returns in this quote: 'seek and destroy standby power. Stand in each room in your house and listen for the tell-tale hum of money and energy being steadily burnt up'. Dave Reay, author of Climate Change Begins at Home, quoted by the Green Guy, 'Your Ethical Tips: turn off standby', March 30, 2006, thegreenguy.typepad.com/thegreenguy/your_ethical_tips/).

9 Anna Shepard, 'Energy for All', August 25, 2006, http://timesonline.typepad.com/eco_worrier/2006/08/energy_for_all.html

${ }^{10}$ Nigel, 'Watt fun: smart meter games', June 19th, 2007, http://www.nigelsecostore.com/blog/2007/06/19/108/ 
11 The Greening of Hedgerley Wood, 'Great Gadgets', 12 April, 2006,

http:/www.hedgerley.net/greening/?p=64 The BBC reported a similar view: 'When people can see how much energy and money they are saving when they switch off the TV rather than leaving it on standby, they immediately become more engaged in the whole issue of energy efficiency'. Mark Kinver, 'Bringing meters out of the closet', 18 May, 2006, http://news.bbc.co.uk/1/hi/sci/tech/4754109.stm

12 This may also open up further questions about the appeal to the environment as an "external authority" in these practices, and the consequences for the type of consumer-citizen being performed here. Where the postliberal citizen-consumer has been described as self-regulating, self-validating and consequently rather self-absorbed, green living experiments present us with an implicated subject, tied into the physical, economic and environmental assemblages of energy use.

13 This project also involves the more specific attempt to break with a tendency of critical theory, that of viewing objects negatively, especially scientific and technological ones. Thus, many object-centred accounts on social life explicitly seek to dismantle the conception of objects as forces of rationalisation, individualisation, atomisation, privatisation, instrumentalization, and so on (Knorr Cetina, 1997). These accounts emphasise the affordances of objects to enable alternative modes of involvement, which are then said to be more creative and experimental, as they operate in a material-affective register, and thereby facilitate forms of involvement that precisely go under-appreciated in predominant, modern conceptions of involvement, which tend to emphasise language and deliberation as the plane on which social, political and moral interaction takes place.

${ }^{14}$ More generally speaking, much work in ANT upholds the analytical distinction between the messy proliferation of stuff and attachments on the 'ground level', and the preservation of modern institutional forms of science, democracy and so on, on another, 'higher level.

${ }^{15}$ One could say that a sociology committed to ontology, as opposed to an'epistemic sociology', is a sociology that operates in both these registers, and refuses to choose between them. Indeed, this is what John Law seems to have in mind when he speaks of 'ontological politics': a sociology that is 'doubly aware', of, on the one hand, the historical ability of scientific practices to change the world, and, on the other hand the importance of granting conceptual recognition to entities that aren't granted much importance in predominant versions of the real (Law, 2004).

${ }^{16}$ There is of course a way in which the insertion in domestic practices of smart electricity meters can be understood in terms of the 'domestication' of techno-science in society as described in actornetwork theory. These devices can be said to prepare the social 'ground' by material means, for the extension of a particular techno-scientific network, that of energy monitoring. However, what such an account does not consider, and what I am concerned with here, is the extent to which entanglement is something performed, i.e. a construct in itself, of which the articulation depends on the deployment of devices and formats of publicity.

${ }^{17}$ Green Guy, 'Eco kettle deathmatch (AKA reviews of Tefal Quick Cup, Eco Kettle \& Plunger Kettle)', August 16, 2007 http://thegreenguy.typepad.com/thegreenguy/2007/08/eco-kettle-thre.html 
${ }^{18} 21^{\text {st }}$ Century Mommy, 'Easter Eggs Unwrapped', March 1, 2008,

http://21 stcenturymummy.blogspot.com/2008/03/easter-eggs-unwrapped.html

${ }^{19}$ Green As A Thistle, 'Water heater meter made better (Day 222)', October 8, 2007, http://greenasathistle.com/2007/10/08/water-heater-meter-made-better-day-222/

${ }^{20}$ Suitably Despairing, '37 Consequences of Going Green', November 26, 2007, http://suitablydespairing.blogspot.com/2007/11/37-consequences-of-going-green.html ${ }^{21}$ Suitably Despairing, 'Smarter Than Your Average Meter', February 07, 2008, http://suitablydespairing.blogspot.com/2008/02/smarter-than-your-average-meter.html ${ }^{22}$ Green As A Thistle, 'Green Recap: September', September 30, 2007, http://greenasathistle.com/2007/09/30/green-recap-september/ 